\title{
Prognostic value of immune cells in the tumor microenvironment of early-stage lung cancer: a meta-analysis
}

\author{
Stephanie Tuminello ${ }^{1}$, Rajwanth Veluswamy ${ }^{1,2}$, Wil Lieberman-Cribbin ${ }^{1}$, Sacha \\ Gnjatic $^{2,3,4}$, Francesca Petralia ${ }^{5}$, Pei Wang ${ }^{5}$, Raja Flores ${ }^{6}$ and Emanuela Taioli ${ }^{1,6,7}$ \\ ${ }^{1}$ Institute for Translational Epidemiology and Department of Population Health Science and Policy, Icahn School of Medicine \\ at Mount Sinai, New York, NY, USA \\ ${ }^{2}$ Department of Medicine, Hematology and Medical Oncology, Icahn School of Medicine at Mount Sinai, New York, NY, USA \\ ${ }^{3}$ Department of Oncological Sciences, Icahn School of Medicine at Mount Sinai, New York, NY, USA \\ ${ }^{4}$ Precision Immunology Institute, Icahn School of Medicine at Mount Sinai, New York, NY, USA \\ ${ }^{5}$ Department of Genetics and Genomic Science, Icahn School of Medicine at Mount Sinai, New York, NY, USA \\ ${ }^{6}$ Department of Thoracic Surgery, Icahn School of Medicine at Mount Sinai, New York, NY, USA \\ ${ }^{7}$ Tisch Cancer Institute, Icahn School of Medicine at Mount Sinai, New York, NY, USA \\ Correspondence to: Emanuela Taioli, email: Emanuela.taioli@mountsinai.org
}

Keywords: NSCLC; immune contexture; tumor microenvironment; TILS

Received: September 18, 2019 Accepted: December 05, $2019 \quad$ Published: December 24, 2019

Copyright: Tuminello et al. This is an open-access article distributed under the terms of the Creative Commons Attribution License 3.0 (CC BY 3.0), which permits unrestricted use, distribution, and reproduction in any medium, provided the original author and source are credited.

\section{ABSTRACT}

Background: Early-stage non-small cell lung cancer (NSCLC) patients carry significant risk of recurrence post-surgery. In-depth characterization of the immune tumor microenvironment (TME) can have prognostic value. This study aimed to evaluate the association of individual immune cell types in the TME with clinical outcomes in surgically resected, early-stage NSCLC.

Methods: We performed a systematic literature search of the National Library of Medicine database through November 2019, investigating predefined biomarkers (CD3+ T cells, CD4+ T helper cells, CD8+ cytotoxic T cells, CD20+ B cells, CD56+ \& CD57+ Natural Killer (NK) cells, CD68+ Tissue Associated Macrophages (TAMS), FoxP3+ $\mathrm{T}$ regulatory cells, and Mast Cells (MC)), and their association with survival following PRISMA guidelines.

Results: Studies that adjusted for important clinical covariates (such as stage and age) showed that higher levels of CD8+ cytotoxic $\mathrm{T}$ cells were associated with improved OS (HR $=0.68 ; 95 \%$ CI, 0.50-0.93) and DFS (HR $=0.60 ; 95 \%$ CI, $0.41-$ 0.87 ), while increased CD20+ B cells (HR $=0.16 ; 95 \%$ CI, 0.04-0.64) and CD 56/57+ NK cells $(H R=0.50 ; 95 \% C I, 0.26-0.95)$ were associated with improved OS; lung cancers with increased FoxP3 $+\mathrm{T}$ regulatory cells $(\mathrm{HR}=2.22 ; 95 \% \mathrm{CI}, 1.47-3.34)$ had worse OS.

Conclusions: Immune cell components of the TME have prognostic value in early-stage, surgically resected NSCLC, and may reveal which patients are more likely to need additional systemic treatment, including immunotherapy. Clinical covariates need to be considered when evaluating the prognostic value of immune cells in the TME.

\section{INTRODUCTION}

Immune cells within the tumor microenvironment (TME) play an important role in the development, progression and outcomes of non-small cell lung cancer
(NSCLC). Innate and adaptive immune cells are able to detect and eliminate malignant transformed cells through the process of immunosurveillance [1]. However, lung cancers that become clinically apparent acquire resistance mechanisms to escape the anti-tumor immune response 
[1-3]. The relative balance of antagonistic effector (i.e., $\mathrm{CD} 8+$ cytotoxic $\mathrm{T}$ cells) and regulatory (i.e., FoxP3+ T regulatory cells [Tregs]) immune cell subpopulations may tilt the TME to be either detrimental or supportive of tumorigenesis, and will have a profound impact on the tumor's eventual destiny [4]. Therefore in-depth characterization of the immune cell composition of the TME is critical to understanding cancer outcomes and may help guide treatment decisions for lung cancer patients.

Resection of early stage NSCLC represents the best opportunity for meaningful long-term survival and cure. However, despite complete removal of all detectable disease, there remains a significant risk of lung cancer recurrence [5]. Predicting which patients are most likely to have recurrence following surgery is of great clinical importance. Patients within the same TNM stage exhibit wide variations in recurrence rates [5]. Efforts to improve post-surgical outcomes using adjuvant chemotherapy have only provided marginal benefit in a subset of patients, while exposing all patients to significant toxicity. New prognostic biomarkers based on immune cell signatures that predict survival outcomes of early stage NSCLC can help identify patients that are most likely to receive benefit from additional systemic treatment, including neoadjuvant or adjuvant immunotherapies which are now being studied.

A number of retrospective studies have shown individual immune cells within the TME are associated with survival in various malignancies. In colorectal cancers, the type and density of tumor infiltrating lymphocytes (TILs) were found to be more powerful prognostic factors than standard anatomical staging criteria (i.e., TNM) [6]. While CD8+ TILs have been the most studied, mounting data is demonstrating many other immune cell types in the TME also play an important role in cancer outcomes [7]. However, findings from these studies are often not consistent and are limited by small sample size. Three previous meta-analyses evaluating the association between immune cells in lung cancer outcomes are also limited because they included studies on patients with both local and advanced disease and did not account for potentially important clinical confounders [8-10].

Here, we have conducted a meta-analysis of studies evaluating the association of individual immune cell types in the TME with clinical outcomes of surgically resected, early stage NSCLC in order to determine novel prognostic biomarkers for this subset of patients.

\section{MATERIALS AND METHODS}

\section{Search strategy}

We conducted a systematic literature search of the National Library of Medicine database to search for all original, retrospective observational studies reporting postoperative survival outcomes of surgically resected, stage I-III NSCLC patients according to immune cell biomarkers (measured by immunohistochemistry $[\mathrm{IHC}])$. There were no date restrictions and the search was finalized in November 2019. Additionally, the cited references of each study (including published reviews and other meta-analyses) were reviewed and evaluated for eligibility. The specific immune cell types studied were selected based on prior literature showing their role in lung cancer prognosis and included: $\mathrm{CD} 3+\mathrm{T}$ cells, $\mathrm{CD} 4+$ T helper cells, CD8+ cytotoxic T cells, CD20+ B cells, CD56+ \& CD57+ Natural Killer (NK) cells, CD68+ Tissue Associated Macrophages (TAMS), FoxP3+ T regulatory cells, and Mast Cells (MC). For each of these biomarkers the search terms included: the relevant biomarker, "lung cancer", and "survival". A separate Medline search was performed for each biomarker.

\section{Selection criteria}

Articles were first screened for relevancy within the scope of the project by independent review of titles and abstracts by two reviewers (ST and WLC). Articles that met qualification underwent further scrutiny through full text review to assure they met all the selection criteria. Disagreements in screening and selection were adjudicated by group consensus involving a third reviewer (ET). Studies were considered eligible for inclusion in this systematic review if they reported on: 1) human subjects, 2) stage I-III NSCLC patients who underwent surgical resection, 3) at least 10 patients, 4) survival data for at least one of the predefined biomarkers or provided sufficient data to estimate survival, and 5) follow-up of at least 4 years. Outcomes of interest were overall survival (OS) and disease-free survival (DFS), either as unadjusted estimates or after adjustment for clinical covariates.

\section{Data extraction}

All relevant descriptive information was extracted from each study to create a standardized tabular summary, including author, year of publication, biomarker data, tumor histology, tumor stage, duration of follow-up, number of patients included, gender (when reported), smoking status (when reported), and hazard ratio [HR] and $95 \%$ confidence interval [CI]) for OS and/or DFS. When studies reported separate survival for immune cell biomarkers in the tumor compartment and the stromal compartment, tumor HR was preferentially chosen over the stromal HR as tumor infiltrating cells are likely more clinically relevant.

\section{Statistical methods}

A meta-analysis was conducted using a linear mixed-effects model to determine the meta-estimate of the average effect, either OS or DFS [11]. The presence 
of heterogeneity across studies was tested with the Q and $\mathrm{I}^{2}$ statistics [12]. The results of the meta-analyses were graphically summarized using forest plots created with the metafor package in R Studio (version 3.2.2; R Foundation for Statistical Computing, Vienna, Austria) [13].

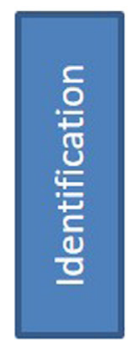

Record identified via PubMed and
reference lists of previously
published research $(\mathrm{n}=2650)$
(CD3: $241 ;$ CD20: $72 ; \mathrm{CD} 4: 565 ;$
CD8: 768; CD56 \& CD57: 117;
CD68: 686; FoxP3: $133 ;$ Mast: 68$)$

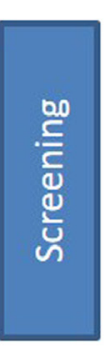

\section{Full-text articles assessed for} eligibility

( $n=511$ )

(CD3: 58; CD4: 165; CD8: 101; CD20: 20; CD56 \& CD57: 40; CD68: 69; FoxP3: 36; Mast: 22)
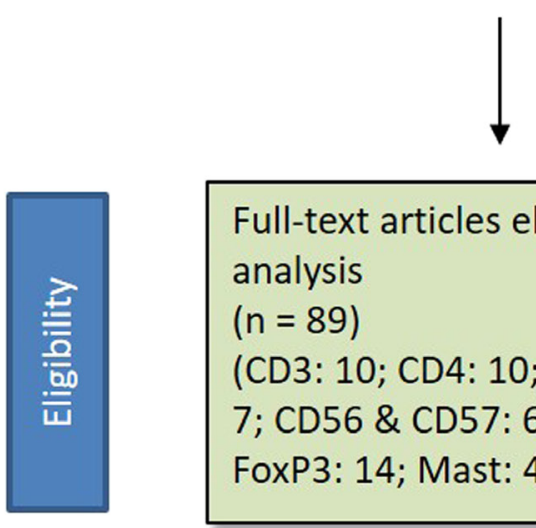

\section{Full-text articles eligible for} analysis

( $n=89$ )

(CD3: 10; CD4: 10; CD8: 26; CD20: 7; CD56 \& CD57: 6; CD68: 12; FoxP3: 14; Mast: 4)

\section{RESULTS}

We identified and screened for relevance 2,650 studies; 2,139 of them were irrelevant to the aims of the study. The full text of the remaining 511 articles were
Records Excluded:

Irrelevant to aims $(n=2139)$

(CD3: 183; CD4: 400; CD8: 667;

CD20: 52; CD56 \& CD57: 77; CD68:

617; FoxP3: 97; Mast: 46)
Full-text articles excluded ( $n=422$ ) (CD3: 48; CD4: 155; CD8: 75; CD20: 13; CD56 \& CD57: 34; CD68: 57; FoxP3: 22; Mast: 18)

\section{Exclusion reasons:}

Survival follow-up < 4 years: 4 Survival data not provided: 210 No Immune-related Biomarker present: 46

Meta Analysis: 12

< 10 Patients: 4

Not Stage I-III NSCLC: 146
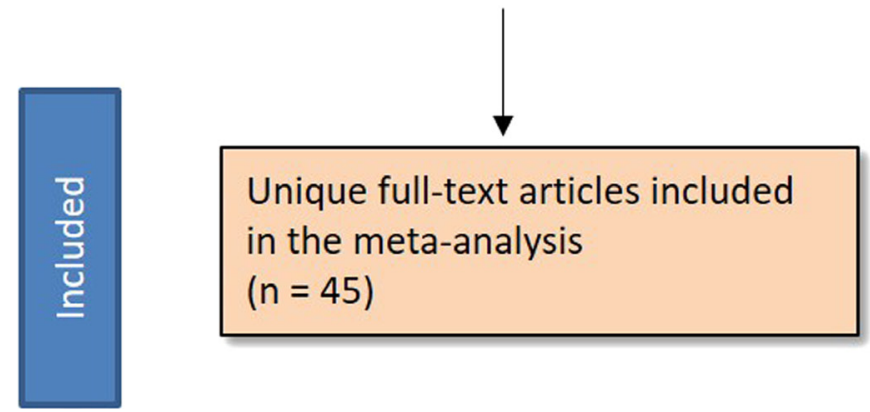

Figure 1: PRISMA. * Eligibility Criteria 1) human subjects, 2) stage I-III NSCLC patients who underwent surgical resection, 3) at least 10 patients, 4) survival data for at least one of the predefined biomarkers or provided sufficient data to estimate survival, and 5) follow-up of at least 4 years. 
reviewed for inclusion, and 45 unique studies were found to be eligible, accounting for 8,471 patients (see Figure 1 for Preferred Reporting Items for Systematic Reviews and Meta-analyses [PRISMA] guidelines). Reasons for ineligibility included having reported survival less than 4 years after surgical resection, inclusion of stage IV NSCLC cases, and not having reported a HR and 95\% CI. Of the included studies, 22 reported survival measures for multiple biomarkers of interest, and 16 studies reported both unadjusted and adjusted HRs (Table 1).

\section{CD3}

The CD3 complex is a defining feature of $\mathrm{T}$ cell lineage. $\mathrm{T}$ lymphocytes are an important aspect of adaptive immunity, subsets of which accomplish various immune system functions [14]. Ten eligible studies $(n=1,385$ patients) reported on $\mathrm{CD} 3+\mathrm{T}$ lymphocytes as a prognostic biomarker. Of these, 7 articles reported unadjusted OS HRs ( $n=1,108), 5$ articles unadjusted DFS HR information $(n=415)$, and 3 articles reported adjusted OS HRs $(n=428)$; no articles reported an adjusted DFS HR estimate.

\section{CD4}

CD4+ T helper cells function as part of the adaptive immune system, where they are involved in priming the immune response through their interaction with major histocompatibility complex (MHC) class II proteins on antigen presenting cells (APCs). Upon activation, they differentiate and release a variety of cytokines to help B cells make antibodies, induce macrophage activity, and recruit neutrophils, eosinophils and basophils [15]. There were 10 studies ( $n=1,496$ patients) on CD4+ T helper cells as a prognostic maker in NSCLC patients. Five articles reported unadjusted $\operatorname{OS} \operatorname{HR}(n=1,037)$ and 3 articles reported unadjusted DFS $(n=466)$. Six articles reported an adjusted OS HR $(n=699)$, while only 1 article gave an adjusted DFS estimate $(n=105)$.

\section{CD8}

CD8+ cytotoxic $\mathrm{T}$ cells recognize antigen peptides presented on MHC class I molecules and are critical for immune defense against intracellular pathogens (i.e., viruses, bacteria) and for tumor surveillance [16]. There were 26 studies ( $n=5,624$ patients) that provided HR estimates for the association between CD8+ cytotoxic T cells and survival in stage I-III NSCLC patients. Fifteen of these articles gave unadjusted OS estimates $(n=3,317)$ and 8 reported on unadjusted DFS $(n=1,603)$. Thirteen articles gave an adjusted OS HR estimate $(n=2,456)$, while 9 reported an adjusted DFS HR $(n=2,596)$.

\section{CD20}

CD20 is expressed on the surface of B lymphocytes, which provide humoral immunity through the production of antibodies. The specific function of tumor infiltrating B cells is still being explored, though it's suggested that these cells play a role in anti-tumor immunity through either directly presenting antigens to $\mathrm{T}$ cells or by generating tumor antigenspecific antibodies that form immune complexes with tumor antigens that are presented by professional APCs [17]. Seven eligible studies $(n=1,058)$ provided HRs on CD20+ B cells as a prognostic biomarker in NSCLC; 5 reported unadjusted OS $(n=897)$ and 4 reported unadjusted DFS $(n=540)$. Only one article reported an estimate for adjusted OS $(n=113)$ or adjusted DFS $(n=218)$.

\section{FoxP3}

T regulatory cells expressing FoxP3 are important for maintaining immune homeostasis by suppressing the proliferation and activation of cytotoxic $\mathrm{T}$ cell response [18]. There were 14 eligible ( $n=2,464$ patients) articles that reported on the predictive value of FoxP3+ T regulatory cells for survival; 9 articles included unadjusted OS $(n=1,547), 3$ reported unadjusted DFS $(n=5080), 7$ reported adjusted OS $(n=934)$ and 3 reported unadjusted DFS $(n=683)$.

\section{CD56 and 57 (NK Cells)}

CD56/57 expressing NK cells, a part of the innate immune system, are capable of quickly recognizing and killing both infected and malignant cells that have lost their MHC I receptors, without priming or prior activation [19]. Six articles reported on survival measures for CD56+ $\&$ CD57+ NK cells $(n=622)$. Three of these reported unadjusted OS $(n=258)$ and 1 reported unadjusted DFS $(n=84)$. Four articles reported adjusted OS $(n=443)$ with 2 reporting adjusted DFS $(n=280)$.

\section{CD68}

TAMS (as identified by CD68 antibodies) are thought to be driven by immunosuppressive cytokines such as IL-10 and TGF-beta and have been associated with suppressing $\mathrm{T}$ cell tumor response and promoting tumor growth and spread [20]. There were 12 eligible articles $(n=1,699)$; 6 reported unadjusted OS $(n=922), 1$ study reported on unadjusted DFS $(n=137)$. Seven articles reported adjusted OS $(n=716)$, and 6 reported adjusted DFS $(n=861)$.

\section{MCs}

When activated, MCs release inflammatory mediators, increasing vascular permeability and recruiting other immune cells [21]. Their role in cancer development, however, is largely unknown. There were 4 unique eligible articles ( $n=771$ patients) that investigated OS according to MC infiltration. Three unique articles reported an unadjusted OS $(n=591)$, with only one study reporting unadjusted DFS 
Table 1: Characteristics of included studies

\begin{tabular}{|c|c|c|c|c|c|c|c|c|c|c|c|}
\hline Study, Year & Biomarker & Location & Outcome & HR & $\begin{array}{c}\text { Covariates in } \\
\text { adjustment model }\end{array}$ & $\begin{array}{c}n \text { of } \\
\text { Patients }\end{array}$ & Male (\%) & $\begin{array}{l}\text { Stage } \\
(\%)\end{array}$ & $\begin{array}{l}\text { Histology } \\
(\%)\end{array}$ & $\begin{array}{l}\text { Smoking } \\
\text { Status }\end{array}$ & Cutoff Value \\
\hline $\begin{array}{l}\text { Takanami, } \\
2000[25]\end{array}$ & MCs & Tumor & OS & Adj & $\begin{array}{c}\text { gender, } \mathrm{T}, \mathrm{N}, \\
\text { differentiation, } \\
\text { microvascular density }\end{array}$ & 180 & 56 & $\begin{array}{l}\text { I: } 55 \\
\text { II: } 14 \\
\text { III: } 31\end{array}$ & ADC: 100 & NR & $\mathrm{MCD}>21$ \\
\hline $\begin{array}{l}\text { Pelletier, } \\
2001[26]\end{array}$ & CD20 & Peritumor & OS & $\overline{\text { Adj }}$ & $\begin{array}{l}\text { stage, histology, } \\
\text { gender }\end{array}$ & 113 & 60 & $\begin{array}{l}\text { I: } 58 \\
\text { II: } 18 \\
\text { III: } 24\end{array}$ & $\begin{array}{l}\text { ADC: } 50 \\
\text { SCC: } 42 \\
\text { LCC: } 3 \\
\text { Other: } 5\end{array}$ & Current: $92 \%$ & $>10 \%$ \\
\hline $\begin{array}{c}\text { Kojima, } 2002 \\
{[27]}\end{array}$ & CD68 MCs & Intratumor & OS & Unadj and Adj & $\begin{array}{l}\text { VEGF, microvessel } \\
\text { density }\end{array}$ & 132 & 67 & I: 100 & $\begin{array}{l}\text { ADC: } 71 \\
\text { SCC: } 29\end{array}$ & NR & Mean \\
\hline $\begin{array}{l}\text { Villegas, } \\
2002[28]\end{array}$ & CD57 & Intratumor & OS & Unadj and Adj & $\begin{array}{l}\text { stage, age, endoscopy } \\
\text { localization }\end{array}$ & 50 & 98 & $\begin{array}{l}\text { I: } 82 \\
\text { II: } 12 \\
\text { III: } 6\end{array}$ & SCC: 100 & $\begin{array}{c}\text { Current: } 74 \% \\
\text { Former: } 22 \% \\
\text { Never: } 4 \% \\
\end{array}$ & Median \\
\hline $\begin{array}{c}\text { Pelosi, } 2004 \\
{[29]}\end{array}$ & $\mathrm{MCs}$ & Tumor & $\begin{array}{l}\text { OS \& } \\
\text { DFS }\end{array}$ & Unadj and Adj & $\begin{array}{l}\text { age, diameter, pT, } \\
\text { Ki-67 labelling index, } \\
\text { HER-2, tumor grade, } \\
\text { symptoms, blc-2, } \\
\text { synaptophysin }\end{array}$ & 201 & 91 & I: 100 & $\begin{array}{l}\text { ADC: } 44 \\
\text { SCC: } 56\end{array}$ & NR & $\geq 5 \%$ \\
\hline $\begin{array}{c}\text { Kojima, } 2005 \\
{[30]}\end{array}$ & CD68 MCs & Tumor & & $\begin{array}{l}\text { Unadj and Adj } \\
\text { (adenocarcinoma } \\
\text { only) }\end{array}$ & $\begin{array}{c}\text { tumor VEGF, tumor } \\
\text { VEGF-C, tumor } \\
\text { VEGFR-3, microvessel } \\
\text { density } \\
\end{array}$ & 129 & 48 & I: 100 & ADC: 100 & $\begin{array}{c}\text { Smoker: } 40 \% \\
\text { Non-smoker: } \\
60 \%\end{array}$ & $\begin{array}{c}\text { Staining score } \\
>3\end{array}$ \\
\hline $\begin{array}{l}\text { Petersen, } \\
2006[31]\end{array}$ & $\mathrm{CD} 3$ & Tumor & DFS & Unadj & $\mathrm{n} / \mathrm{a}$ & 64 & 53 & I: 100 & $\begin{array}{l}\text { ADC: } 46 \\
\text { SCC: } 34 \\
\text { Other: } 19\end{array}$ & $\begin{array}{l}\text { Mean pack- } \\
\text { year } 51 \pm 33\end{array}$ & $\begin{array}{l}\text { Score } \geq 2 \\
\text { (median) }\end{array}$ \\
\hline $\begin{array}{l}\text { Kikuchi, } \\
2007[32]\end{array}$ & $\begin{array}{l}\text { CD8 } \\
\text { CD56 }\end{array}$ & Cancer-Nest & OS & Unadj & $\mathrm{n} / \mathrm{a}$ & 161 & 68 & $\begin{array}{c}\text { I: } 59^{*} \\
\text { II/III/IV: } \\
\quad 41\end{array}$ & $\begin{array}{l}\text { ADC: } 52 \\
\text { SCC: } 42 \\
\text { Other: } 6\end{array}$ & $\begin{array}{c}\text { Never: } 24 \% \\
\text { Ever: } 67 \% \\
\text { Unknown: } 9 \%\end{array}$ & $\begin{array}{c}\text { 1-cell } \\
\text { increment }\end{array}$ \\
\hline $\begin{array}{c}\text { Dieu- } \\
\text { Nosjean, } \\
2008[33]\end{array}$ & $\begin{array}{l}\text { CD3 } \\
\text { CD20 }\end{array}$ & Tumor & $\begin{array}{l}\text { OS \& } \\
\text { DFS }\end{array}$ & Unadj & $\mathrm{n} / \mathrm{a}$ & 74 & 81 & $\begin{array}{l}\text { I: } 84 \\
\text { II: } 16\end{array}$ & $\begin{array}{l}\text { ADC: } 62 \\
\text { SCC: } 38\end{array}$ & $\begin{array}{c}\text { Current: } 91 \% \\
\text { Never: } 9 \%\end{array}$ & 1.5 mean score \\
\hline $\begin{array}{l}\text { Shimizu, } \\
2010[34]\end{array}$ & FoxP3 & Intratumor & DFS & Adj & $\begin{array}{l}\text { nodal involvement, } \\
\text { COX-2 expression }\end{array}$ & 100 & 60 & $\begin{array}{l}\text { I: } 68 \\
\text { II: } 14 \\
\text { III: } 18 \\
\end{array}$ & $\begin{array}{l}\text { ADC: } 69 \\
\text { SCC: } 31\end{array}$ & NR & $\geq 3 \%$ \\
\hline $\begin{array}{c}\text { da Costa } \\
\text { Souza, } 2012 \\
{[35]}\end{array}$ & $\begin{array}{l}\mathrm{CD} 4 \\
\mathrm{CD} 8 \\
\mathrm{CD} 68\end{array}$ & & OS & Adj & $\begin{array}{l}\text { stage and histological } \\
\text { type }\end{array}$ & 65 & 69 & $\begin{array}{l}\text { I: } 31 \\
\text { II: } 51 \\
\text { III: } 18\end{array}$ & $\begin{array}{l}\text { ADC: } 58 \\
\text { SCC: } 31 \\
\text { LCC: } 11\end{array}$ & $\begin{array}{l}\text { Pack-years } \\
\text { median } \\
41(0-120)\end{array}$ & $\begin{array}{c}\text { CD4: } \geq 16.1 \% \\
\text { CD8: } \geq 1.8 \% \\
\text { CD68: } \geq 4.5 \%\end{array}$ \\
\hline $\begin{array}{l}\text { Hanagiri, } \\
2013[36]\end{array}$ & FoxP3 & $\begin{array}{l}\text { Regional } \\
\text { Lymph } \\
\text { Nodes }\end{array}$ & OS & Unadj and Adj & $\begin{array}{l}\text { gender, pack-year } \\
\text { index, T factor, } \mathrm{N} \\
\text { factor }\end{array}$ & 158 & 65 & $\begin{array}{l}\text { I: } 72 \\
\text { II: } 11 \\
\text { III: } 19 \\
\end{array}$ & $\begin{array}{l}\text { ADC: } 59 \\
\text { SCC: } 22 \\
\text { Other: } 9\end{array}$ & NR & $\begin{array}{c}>0.5 \% \text { PBL } \\
>1.1 \% \text { RLNL }\end{array}$ \\
\hline $\begin{array}{c}\text { Suzuki, } 2013 \\
{[37]}\end{array}$ & FoxP3 & Stroma & DFS & Unadj and Adj & $\begin{array}{l}\text { gender, stage, } \\
\text { lymphatic invasion, } \\
\text { IL-12R, IL-7R }\end{array}$ & $\begin{array}{c}956 \\
(478)\end{array}$ & 36 & I: 100 & ADC: 100 & $\begin{array}{c}\text { Current: } 16 \% \\
\text { Former: } 69 \% \\
\text { Never: } 15 \% \\
\end{array}$ & Score $\geq 2$ \\
\hline $\begin{array}{c}\text { Feng, } 2014 \\
{[38]}\end{array}$ & CD68 & $\begin{array}{l}\text { Islet and } \\
\text { Stroma }\end{array}$ & $\begin{array}{l}\text { OS \& } \\
\text { DFS }\end{array}$ & Adj & $\begin{array}{c}\text { mediastinal down } \\
\text { staging, islet/stromal } \\
\text { machrophage ratio }\end{array}$ & 28 & 54 & III: 100 & $\begin{array}{l}\text { ADC: } 70 \\
\text { SCC: } 21\end{array}$ & $\begin{array}{c}\text { Smoker: } 39 \% \\
\text { Never: } 61 \%\end{array}$ & median \\
\hline $\begin{array}{l}\text { Germain, } \\
2014 \text { [39] }\end{array}$ & $\mathrm{CD} 20$ & Tumor & OS & Unadj & $\mathrm{n} / \mathrm{a}$ & 74 & 81 & $\begin{array}{l}\text { I: } 84 \\
\text { II: } 16\end{array}$ & $\begin{array}{l}\text { ADC: } 62 \\
\text { SCC: } 38\end{array}$ & $\begin{array}{c}\text { Current: } 91 \% \\
\text { Never: } 9 \%\end{array}$ & $\begin{array}{c}\text { CD20: } \\
0.0255 \mathrm{~mm}^{2} / \\
\text { tumor IPF }\end{array}$ \\
\hline $\begin{array}{l}\text { Hanagiri, } \\
2014[40]\end{array}$ & FoxP3 & $\begin{array}{l}\text { Regional } \\
\text { Lymph } \\
\text { Nodes }\end{array}$ & OS & Unadj and Adj & gender, age, histology & 131 & 57 & I: 100 & $\begin{array}{l}\text { ADC: } 76 \\
\text { SCC: } 16 \\
\text { Other: } 8\end{array}$ & NR & $\begin{array}{c}\text { Relative } \\
\text { expression }> \\
0.06\end{array}$ \\
\hline $\begin{array}{l}\text { Lee, } 2014 \\
\quad[41]\end{array}$ & CD68 & & DFS & Adj & $\begin{array}{l}\text { procedure, stage, } \\
\text { CD68, FoxP3/CD3 }\end{array}$ & 151 & 40 & I: 100 & $\begin{array}{l}\text { ADC: } 77 \\
\text { SCC: } 23\end{array}$ & $\begin{array}{c}\text { Current: } 7 \% \\
\text { Former: } 72 \% \\
\text { Never: } 21 \%\end{array}$ & Score $\geq 2$ \\
\hline $\begin{array}{c}\text { Djenidi, } 2015 \\
{[42]}\end{array}$ & $\begin{array}{l}\mathrm{CD} 3 \\
\mathrm{CD} 8\end{array}$ & $\begin{array}{l}\text { Total (tumor } \\
+ \text { stroma) }\end{array}$ & $\begin{array}{l}\text { OS \& } \\
\text { DFS }\end{array}$ & Unadj & $\mathrm{n} / \mathrm{a}$ & 101 & 68 & I: 100 & $\begin{array}{l}\text { ADC: } 45 \\
\text { SCC: } 42 \\
\text { Other: } 13\end{array}$ & Ever: $89 \%$ & $\begin{array}{l}\text { Continuous } \\
\text { variables }\end{array}$ \\
\hline $\begin{array}{c}\text { Hernandez- } \\
\text { Prieto, } 2015 \\
{[43]}\end{array}$ & $\begin{array}{c}\text { CD3 } \\
\text { CD4 } \\
\text { CD8 } \\
\text { CD20 } \\
\text { CD57 }\end{array}$ & Stroma & DFS & Unadj & $\mathrm{n} / \mathrm{a}$ & 84 & 86 & $\begin{array}{l}\text { I: } 71 \\
\text { II: } 29\end{array}$ & $\begin{array}{l}\text { ADC: } 48 \\
\text { SCC: } 46 \\
\text { LCC: } 2 \\
\text { Other: } 4\end{array}$ & $\begin{array}{c}\text { Current: } 43 \% \\
\text { Former: } 51 \% \\
\text { Never: } 6 \%\end{array}$ & $\begin{array}{c}\text { Moderate } 10 \% \\
\text { Strong } 20 \%\end{array}$ \\
\hline
\end{tabular}




\begin{tabular}{|c|c|c|c|c|c|c|c|c|c|c|c|}
\hline \multirow[t]{7}{*}{$\begin{array}{c}\text { Kadota, } 2015 \\
{[44]}\end{array}$} & CD3 & Tumor & OS & Unadj & $\mathrm{n} / \mathrm{a}$ & 331 & 60 & I: 57 & SCC: 100 & $\begin{array}{c}\leq 90 \text { pack-year: } \\
81 \%\end{array}$ & $\begin{array}{l}\text { CD3: High } \\
\quad \geq 50\end{array}$ \\
\hline & $\mathrm{CD} 4$ & & & & & & & II: 28 & & $\begin{array}{c}>90 \text { pack-year: } \\
19 \%\end{array}$ & $\begin{array}{l}\text { CD4: High } \\
\quad \geq 20\end{array}$ \\
\hline & $\mathrm{CD} 8$ & & & & & & & III: 15 & & & $\begin{array}{l}\text { CD8: High } \\
\quad \geq 50\end{array}$ \\
\hline & $\mathrm{CD} 20$ & & & & & & & & & & $\begin{array}{l}\text { CD20: High } \\
\geq 20\end{array}$ \\
\hline & CD68 & & & & & & & & & & $\begin{array}{l}\text { CD68: High } \\
\quad \geq 50\end{array}$ \\
\hline & FoxP3 & & & & & & & & & & $\begin{array}{c}\text { FoxP3: High } \\
\geq 20\end{array}$ \\
\hline & $\begin{array}{l}\text { Neutrophil- } \\
\text { (CD10) }\end{array}$ & & & & & & & & & & $\begin{array}{l}\text { CD10: High } \\
\quad \geq 10\end{array}$ \\
\hline \multirow{3}{*}{$\begin{array}{c}\text { Kim, } 2015 \\
{[45]}\end{array}$} & $\mathrm{CD} 8$ & Tumor & OS \& & Unadj & $\mathrm{n} / \mathrm{a}$ & 331 & 96 & I: 40 & SCC: 100 & Smoker: $91 \%$ & Median \\
\hline & & & DFS & & & & & II: 36 & & Never: $5 \%$ & \\
\hline & & & & & & & & III: 24 & & & \\
\hline \multirow{3}{*}{$\begin{array}{l}\text { Donnem, } \\
2015 \text { [46] }\end{array}$} & $\mathrm{CD} 8$ & Stroma & OS \& & Adj & stage, differentiation, & 797 & 64 & I: 51 & ADC: 48 & NR & High density \\
\hline & & & & & & & & II: 35 & SCC: 45 & & \\
\hline & & & & & & & & III: 15 & LCC: 7 & & \\
\hline \multirow[t]{3}{*}{$\mathrm{Li}, 2015$ [47] } & CD68 & & OS \& & Adj & TNM, N stage, & 159 & 69 & $\mathrm{I}: 23$ & ADC: 26 & Smoker: $31 \%$ & \\
\hline & & & DFS & & $\begin{array}{c}\text { subcarinal lymph node, } \\
n \text { number of nodal }\end{array}$ & & & II: 36 & SCC: 52 & Never: $69 \%$ & \\
\hline & & & & & $\begin{array}{c}\text { stations involved, } \\
\text { number of involved } \\
\text { nodes }\end{array}$ & & & III: 24 & & & \\
\hline \multirow[t]{4}{*}{$\begin{array}{l}\text { O'Callaghan, } \\
2015[48]\end{array}$} & $\mathrm{CD} 3$ & $\mathrm{TI} / \mathrm{S}$ & OS & Unadj and Adj & $\begin{array}{l}\text { tumor size, stage, } \\
\text { lymph node stage, }\end{array}$ & $\begin{array}{c}197 \\
(186)\end{array}$ & 62 & I: 55 & ADC: 45 & $\begin{array}{c}\text { Current \& } \\
\text { Former: } 94 \%\end{array}$ & Median \\
\hline & CD8 & & & & $\begin{array}{l}\text { WHO overall stage, } \\
\text { positive resection }\end{array}$ & & & II: 24 & SCC: 46 & Never: $6 \%$ & \\
\hline & FoxP3 & & & & margins, TI/S & & & III: 21 & LCC: 3 & & \\
\hline & & & & & biomarker ratios & & & & Other: 6 & & \\
\hline \multirow{3}{*}{$\begin{array}{l}\text { Paulsen, } \\
2015 \text { [49] }\end{array}$} & $\mathrm{CD} 8$ & Tumor & OS & Unadj & $\mathrm{n} / \mathrm{a}$ & 536 & 68 & I: 48 & ADC: 38 & Current: $33 \%$ & score of $\geq 2$ \\
\hline & & & & & & & & II: 36 & SCC: 54 & Former: $64 \%$ & \\
\hline & & & & & & & & III: 16 & & Never: $3 \%$ & \\
\hline \multirow[t]{3}{*}{$\begin{array}{c}\text { Tian, } 2015 \\
{[50]}\end{array}$} & $\mathrm{CD} 3$ & Tumor & OS & Adj & $\begin{array}{l}\text { histology, pT, pN, } \\
\text { pTNM stage, CD3, }\end{array}$ & 129 & 71 & $\mathrm{I}: 37$ & ADC: 37 & Smoker: $37 \%$ & $\begin{array}{l}\text { H-score } 0-4= \\
\text { low expression }\end{array}$ \\
\hline & $\mathrm{CD} 8$ & & & & CD8, IL-2 & & & II: 22 & SCC: 47 & Never: $63 \%$ & $\begin{array}{l}\text { H-score } \\
5-12=\text { high } \\
\text { expression }\end{array}$ \\
\hline & & & & & & & & III: 40 & Other: 16 & & \\
\hline \multirow{4}{*}{$\begin{array}{l}\text { Ameratunga, } \\
2016[51]\end{array}$} & $\mathrm{CD} 8$ & Stroma & OS \& & Unadj and Adj & & 527 & 69 & NR & ADC: 55 & Heavy: $73 \%$ & Score of $\%$ \\
\hline & & & & & pneumonectomy & & & & SCC: 34 & Light: $17 \%$ & of positively \\
\hline & & & & & histology, smoking & & & & Other: 11 & Never: $7 \%$ & $>3$ \\
\hline & & & & & $\begin{array}{c}\text { status, CD8+, FOXP3, } \\
\text { PD-L1 }\end{array}$ & & & & & Unknown: 4\% & \\
\hline \multirow[t]{4}{*}{$\begin{array}{l}\text { Kinoshita, } \\
2016[52]\end{array}$} & CD4 & Tumor & $\begin{array}{l}\text { OS \& } \\
\text { DFS }\end{array}$ & $\begin{array}{l}\text { Unadj and Adj } \\
\text { (for CD20 only) }\end{array}$ & $\begin{array}{l}\text { age, diameter, nodal } \\
\text { metastasis, pleural }\end{array}$ & 218 & 65 & I: 71 & ADC: 72 & Ever: $61 \%$ & $\begin{array}{c}\mathrm{CD} 4:>251 \\
\text { cells } / \mathrm{mm}^{2}\end{array}$ \\
\hline & CD8 & & & & invasion, FoxP3/CD4 & & & II: 11 & SCC: 18 & Never: $39 \%$ & $\begin{array}{c}\text { CD8: }>110 \\
\text { cells } / \mathrm{mm}^{2}\end{array}$ \\
\hline & $\mathrm{CD} 20$ & & & & & & & III: 18 & Other: 10 & & $\begin{array}{c}\text { FoxP3: }>163 \\
\text { cells } / \mathrm{mm}^{2}\end{array}$ \\
\hline & FoxP3 & & & & & & & & & & \\
\hline \multirow{3}{*}{$\begin{array}{c}\text { Parra, 2016 } \\
{[53]}\end{array}$} & CD57 & Peri and & OS (CD57 & Adj & tumor stage, adjuvant & 254 & 55 & $\mathrm{I}: 50$ & ADC: 57 & Current: $45 \%$ & Median \\
\hline & CD68 & & $\begin{array}{l}\text { only) \& } \\
\text { DFS }\end{array}$ & & therapy & & & II: 30 & SCC: 43 & Former: $30 \%$ & \\
\hline & & & & & & & & III: 20 & & Never: $17 \%$ & \\
\hline \multirow{3}{*}{$\begin{array}{c}\text { Teng, } 2016 \\
{[54]}\end{array}$} & $\mathrm{CD} 8$ & Tumor & OS \& & Unadj and Adj & high risk, FoxP3/ & 126 & 67 & I: 100 & ADC: 45 & NR & CD3: $\geq 30 \%$ \\
\hline & FoxP3 & & & & & & & & SCC: 33 & & $\begin{array}{c}\text { FoxP3: } \geq 45 / \\
\text { HPF }\end{array}$ \\
\hline & & & & & & & & & LCC: 22 & & \\
\hline \multirow{3}{*}{$\begin{array}{l}\text { Uso, } 2016 \\
{[55]}\end{array}$} & $\mathrm{CD} 8$ & Tumor and & OS \& & Adj & Tumoral CD8+ cells, & 122 & 85 & I: 59 & ADC: 42 & Current: $48 \%$ & CD8: Median \\
\hline & FoxP3 & Str & $\begin{array}{l}\text { DFS (CD8 } \\
\text { only) }\end{array}$ & & $\begin{array}{c}\text { Stromal FOXP3+ } \\
\text { cells, FOXP3+ stroma/ }\end{array}$ & & & II: 21 & SCC: 47 & Former: $38 \%$ & FoxP3: $>10 \%$ \\
\hline & & & & & $\begin{array}{c}\text { CD4+ tumor, FOXP3+ } \\
\text { stroma/CD8+ tumor }\end{array}$ & & & III: 20 & Other: 11 & Never: $14 \%$ & \\
\hline \multirow[t]{3}{*}{$\begin{array}{c}\text { Yang, 2016 } \\
{[56]}\end{array}$} & $\mathrm{CD} 4$ & $\begin{array}{c}\text { Tumor and } \\
\text { Stroma }\end{array}$ & $\begin{array}{l}\text { OS \& } \\
\text { DFS }\end{array}$ & $\overline{\text { Adj }}$ & $\begin{array}{l}\text { age, sex, stage, PD-L1 } \\
\text { expression, Stromal } \\
\text { CD4+ T cell, Stromal }\end{array}$ & 105 & 85 & I: 100 & SCC: 100 & Smoker: $75 \%$ & $\begin{array}{c}\text { CD4: } \geq 5 \% \\
\quad \text { (tumor) \& } \\
\geq 25 \% \text { (stroma) }\end{array}$ \\
\hline & CD8 & & & & $\begin{array}{c}\text { regulatory T cell, } \\
\text { Epithelial CD8+ T cell }\end{array}$ & & & & & $\begin{array}{c}\text { Non Smoker: } \\
25 \%\end{array}$ & $\begin{array}{c}\text { CD8: } \geq 5 \% \\
\quad \text { (tumor) \& } \\
\geq 50 \% \text { (stroma) }\end{array}$ \\
\hline & FoxP3 & & & & & & & & & & FoxP3: $\geq 20 \%$ \\
\hline
\end{tabular}




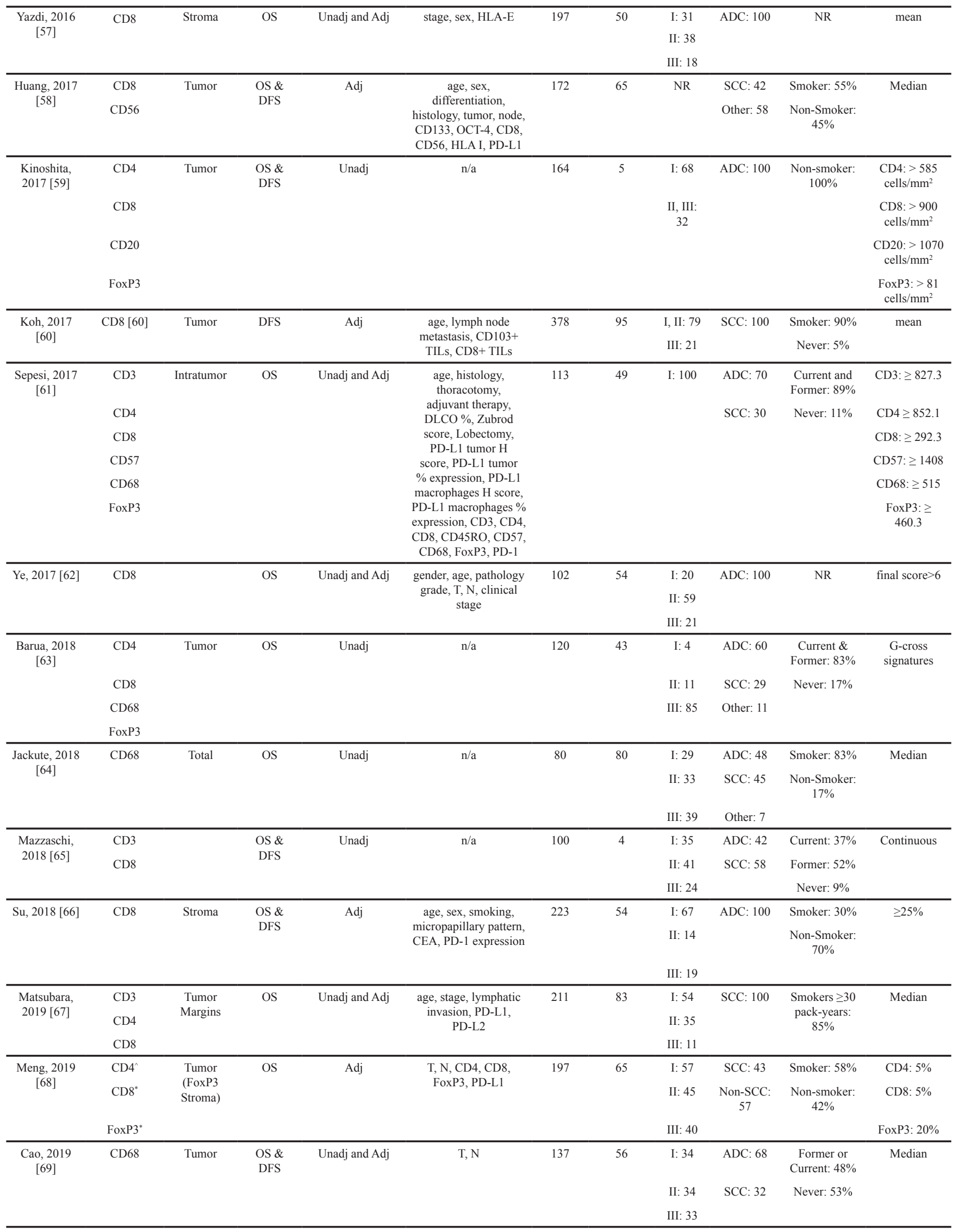

"HR reported for stage I only. "HR reported for squamous only.

${ }^{\#} \mathrm{ADC}=$ adenocarcinoma, $\mathrm{SCC}=$ squamous cell carcinoma, $\mathrm{LCC}=$ large cell carcinoma, $\mathrm{NR}=$ not reported, $\mathrm{n} / \mathrm{a}=$ not applicable, $\mathrm{OS}=$ overall survival, $\mathrm{DFS}=$ disease free survival, $\mathrm{Adj}=$ adjusted for covariates, $\mathrm{Unadj}=$ not adjusted for covariates. 
Table 2: Unadjusted and adjusted pooled survival estimates

\begin{tabular}{|c|c|c|c|c|c|c|c|c|}
\hline \multicolumn{9}{|c|}{ Overall Survival (OS) } \\
\hline Biomarker & $\begin{array}{c}\text { Unadjusted HR } \\
(95 \% \text { CI) }\end{array}$ & $\begin{array}{c}\text { Number } \\
\text { of Articles }\end{array}$ & $n$ & Heterogeneity & $\begin{array}{c}\text { Adjusted HR } \\
\text { (95\% CI) }\end{array}$ & $\begin{array}{c}\text { Number of } \\
\text { Articles }\end{array}$ & $n$ & Heterogeneity \\
\hline CD3 & $0.99(0.87,1.12)$ & 7 & 1,108 & $\begin{array}{c}\mathrm{I}^{2}=0.00 \% \\
\mathrm{Q}=1.64(p=0.90)\end{array}$ & $0.71(0.37,1.37)$ & 3 & 428 & $\begin{array}{c}\mathrm{I}^{2}=0.00 \% \\
\mathrm{Q}=1.76(p=0.42)\end{array}$ \\
\hline CD4 & $0.76(0.44,1.32)$ & 5 & 1,037 & $\begin{array}{c}\mathrm{I}^{2}=34.65 \% \\
\mathrm{Q}=3.47(p=0.19)\end{array}$ & $1.00(0.55,1.81)$ & 6 & 699 & $\begin{array}{c}\mathrm{I}^{2}=33.79 \% \\
\mathrm{Q}=7.55(p=0.18)\end{array}$ \\
\hline CD8 & $0.99(0.95,1.04)$ & 15 & 3,317 & $\begin{array}{c}\mathrm{I}^{2}=0.00 \% \\
\mathrm{Q}=10.96(p=0.69)\end{array}$ & $0.68(0.50,0.93)$ & 13 & 2,456 & $\begin{array}{c}\mathrm{I}^{2}=23.78 \% \\
\mathrm{Q}=15.74(p=0.20)\end{array}$ \\
\hline $\mathrm{CD} 20$ & $0.45(0.22,0.93)$ & 5 & 861 & $\begin{array}{c}\mathrm{I}^{2}=52.29 \% \\
\mathrm{Q}=8.38(p=0.08)\end{array}$ & $0.16(0.04,0.64)$ & 1 & 113 & - \\
\hline FoxP3 & $1.78(1.20,2.64)$ & 9 & 1,547 & $\begin{array}{c}\mathrm{I}^{2}=14.93 \% \\
\mathrm{Q}=9.40(p=0.31)\end{array}$ & $2.22(1.47,3.34)$ & 7 & 934 & $\begin{array}{c}\mathrm{I}^{2}=0.00 \% \\
\mathrm{Q}=4.74(p=0.58)\end{array}$ \\
\hline CD56/CD57 & $0.66(0.35,1.25)$ & 3 & 258 & $\begin{array}{c}\mathrm{I}^{2}=13.63 \% \\
\mathrm{Q}=2.32(p=0.31)\end{array}$ & $0.50(0.26,0.95)$ & 4 & 443 & $\begin{array}{c}\mathrm{I}^{2}=0.00 \% \\
\mathrm{Q}=0.22(p=0.97)\end{array}$ \\
\hline CD68 & $1.36(0.75,2.45)$ & $6^{\#}$ & 922 & $\begin{array}{c}\mathrm{I}^{2}=40.21 \% \\
\mathrm{Q}=10.03(p=0.12)\end{array}$ & $1.13(0.77,1.65)$ & 7 & 716 & $\begin{array}{c}\mathrm{I}^{2}=0.00 \% \\
\mathrm{Q}=4.18(p=0.65)\end{array}$ \\
\hline MCs & $1.81(1.01,3.15)$ & $3^{\wedge}$ & 462 & $\begin{array}{c}\mathrm{I}^{2}=0.00 \% \\
\mathrm{Q}=0.09(p=0.90)\end{array}$ & $2.01(0.88-3.92)$ & 3 & 604 & $\begin{array}{c}\mathrm{I}^{2}=43.99 \% \\
\mathrm{Q}=5.36(p=0.15)\end{array}$ \\
\hline \multicolumn{9}{|c|}{ Disease Free Survival (DFS) } \\
\hline Biomarker & $\begin{array}{c}\text { Unadjusted HR } \\
(95 \% \mathrm{CI})\end{array}$ & $\begin{array}{c}\text { Number } \\
\text { of Articles }\end{array}$ & $n$ & Heterogeneity & $\begin{array}{c}\text { Adjusted HR } \\
(95 \% \mathrm{CI})\end{array}$ & $\begin{array}{l}\text { Number of } \\
\text { Articles }\end{array}$ & $n$ & Heterogeneity \\
\hline CD3 & $0.98(0.86,1.12)$ & 5 & 415 & $\begin{array}{c}\mathrm{I}^{2}=0.00 \% \\
\mathrm{Q}=2.63(p=0.62)\end{array}$ & - & - & - & - \\
\hline $\mathrm{CD} 4$ & $0.72(0.39,1.32)$ & 3 & 466 & $\begin{array}{c}\mathrm{I}^{2}=0.00 \% \\
\mathrm{Q}=0.60(p=0.74)\end{array}$ & $0.59(0.11,3.12)$ & 1 & 105 & - \\
\hline $\mathrm{CD} 8$ & $0.94(0.77,1.16)$ & 8 & 1,630 & $\begin{array}{c}\mathrm{I}^{2}=16.65 \% \\
\mathrm{Q}=8.39(p=0.30)\end{array}$ & $0.60(0.41,0.87)$ & 9 & 2,596 & $\begin{array}{c}\mathrm{I}^{2}=20.43 \% \\
\mathrm{Q}=10.05(p=0.26)\end{array}$ \\
\hline CD20 & $0.57(0.33,1.00)$ & 4 & 540 & $\begin{array}{c}\mathrm{I}^{2}=0.00 \% \\
\mathrm{Q}=0.27(p=0.97)\end{array}$ & $0.51(0.20,1.32)$ & 1 & 218 & - \\
\hline FoxP3 & $1.45(0.81,2.59)$ & 3 & 508 & $\begin{array}{c}\mathrm{I}^{2}=0.00 \% \\
\mathrm{Q}=0.07(p=0.96)\end{array}$ & $2.07(1.10,3.90)$ & 3 & 683 & $\begin{array}{c}\mathrm{I}^{2}=0.00 \% \\
\mathrm{Q}=0.02(p=0.99)\end{array}$ \\
\hline CD56/CD57 & $1.35(0.39,4.66)$ & 1 & 84 & - & $0.59(0.27,1.28)$ & 2 & 280 & $\begin{array}{c}\mathrm{I}^{2}=0.00 \% \\
\mathrm{Q}=0.34(p=0.56)\end{array}$ \\
\hline CD68 & $1.81(0.66,4.92$ & 1 & 137 & - & $1.84(1.02,3.34)$ & $6^{\#}$ & 861 & $\begin{array}{c}\mathrm{I}^{2}=29.96 \% \\
\mathrm{Q}=7.14(p=0.21)\end{array}$ \\
\hline MCs & $2.30(1.20-4.70)$ & 1 & 201 & - & $1.50(0.60,3.60)$ & 1 & 201 & - \\
\hline
\end{tabular}

\#6 unique articles but 7 estimates. For Parra, 2016 adenocarcinoma and squamous histologies were evaluated separately. 3 unique articles but 4 estimates. $\mathrm{HR}>1$ refers to high level of immune cell subtype associated with worse survival.

$(n=201)$. Four articles reported adjusted OS $(n=733)$, while 1 study reported adjusted DFS $(n=201)$.

\section{Immuno-infiltrates and survival}

There were no significant differences between high vs. low CD3+ T cells or CD4+ T Helper cell infiltration in terms of OS or DFS (Table 2; Supplementary Figures 1 and 2). Adjusted data showed that increased levels of CD8 + T cytotoxic cells were predictive of improved OS $\left(\mathrm{HR}_{\mathrm{OS}(\mathrm{adj})}=0.68 ; 95 \% \mathrm{CI}, 0.50-0.93\right)$ and $\mathrm{DFS}\left(\mathrm{HR}_{\mathrm{DFS}}\right.$ (adj) $=0.60 ; 95 \%$ CI, 0.41-0.87; Table 2; Supplementary Figure 3A). However, CD8+ T cells were not significantly associated with improved survival (OS and DFS) in 
unadjusted analysis. Both unadjusted OS and DFS estimates indicated an association between CD20+ B cells and better survival $\left(\mathrm{HR}_{\mathrm{OS} \text { (unadj) }}=0.45 ; 95 \% \mathrm{CI}, 0.22-0.93\right.$ and $\mathrm{HR}_{\mathrm{DFS} \text { (unadj) }}=0.57 ; 95 \% \mathrm{CI}, 0.33-1.00$, respectively). There was only one study reporting adjusted OS, which confirmed the finding $\left(\mathrm{HR}_{\mathrm{OS}(\mathrm{adj})}=0.16 ; 95 \% \mathrm{CI}, 0.04\right.$ 0.64; Table 2; Supplementary Figure 4A). High levels of FoxP3+ Treg lymphocytes were associated with worse OS when looking at both unadjusted $\left(\mathrm{HR}_{\mathrm{OS} \text { (unadj) }}=1.78\right.$; $95 \% \mathrm{CI}, 1.20-2.64)$ and adjusted $\left(\mathrm{HR}_{\mathrm{OS}(\mathrm{adj})}=2.22 ; 95 \%\right.$ CI, 1.47-3.34) data, and with worse DFS (HR DFS (adj) $=$ 2.07; 95\% CI, 1.10-3.90) when adjusting for covariates (Table 2; Supplementary Figure 5A). Patients with a higher level of NK cells (CD56/CD57+) had significantly better adjusted OS than those with lower levels $\left(\mathrm{HR}_{\mathrm{OS} \text { (adj) }}\right.$ $=0.50 ; 95 \%$ CI, 0.26-0.95), although this association was not significant in the meta-estimate of unadjusted studies (Table 2; Supplementary Figure 6A). Increased presence of macrophages $(\mathrm{CD} 68+)$ did not show a statistically significant prognostic value in terms of OS, although CD68+ macrophages were associated with worse adjusted DFS $\left(\mathrm{HR}_{\mathrm{DFS}(\mathrm{adj})}=1.84 ; 95 \% \mathrm{CI}, 1.02-3.34\right)$, (Table 2; Supplementary Figure 7A). Higher levels of MCs were indicative of worse OS in the analysis of adjusted studies $\left(\mathrm{HR}_{\mathrm{OS} \mathrm{(adj)}}=2.13 ; 95 \% \mathrm{CI}, 1.14-3.96\right.$; Table 2; Supplementary Figure 8A).

\section{DISCUSSION}

To our knowledge, this is the first meta-analysis demonstrating immune cell subpopulations within the TME having prognostic value in early-stage NSCLC patients undergoing surgical resection. Furthermore, this meta-analysis is also the first to present findings according to whether or not studies adjusted for clinical covariates. In the analysis of unadjusted studies, only CD20+ B cells were associated with improved OS and DFS, while FOXP3+ Tregs were associated with worse OS. However, when evaluating studies that adjusted for important clinical covariates (such as stage and age), higher levels of CD8+ cytotoxic T cells were associated with improved OS and DFS, and increased CD20+ B cells and CD 56/57+ NK cells were associated with improved OS. Lung cancers with increased FoxP3 $+\mathrm{T}$ regulatory cells or increased MCs had worse OS, and cancers with increased CD68+ macrophages had worse DFS. Our results are in keeping with what is known about the function of these immune cells; we now show these cells appear to have an important role in clinical outcomes of early-stage lung cancer.

Data evaluating the role of immune cells of the TME and lung cancer outcomes mostly come from small case series that are limited by sample size. Three prior metaanalyses attempting to combine the data from these studies have reported improved outcomes with increased CD8+ $\mathrm{T}$ cells and worse outcomes associated with FOXP3+ T regulatory cells [8-10]. However, the impact of CD20+ B cells, CD3+ T cells, CD4+ T cells and TAMs on survival was not consistent across studies. These meta-analyses presented significant heterogeneity by including data from both early- and advanced-stage NSCLC patients, possibly conferring different stages of the immunoediting process. Furthermore, patients with metastatic disease are subject to different treatments strategies (i.e., systemic chemotherapies, immunotherapies, targeted treatments) that can affect both the immune composition of the TME and survival outcomes. Additionally, tissue samples from metastatic disease are typically biopsies (i.e., core or fine needle aspirates), and it is unclear whether immunophenotyping of these samples completely characterizes the TME. Our study overcomes several of these limitations by focusing on the immune cell composition of resected early-stage lung cancers, enabling us to evaluate studies using 1) a more homogenous NSCLC population that is likely treatment naïve (except possibly the small percentage receiving neo-adjuvant chemotherapy) and 2) larger surgical samples, to study the immune composition of the TME in a more comprehensive way. Additionally, given that surgical resection of earlystage lung cancer represents the best chance for cure and long-term survival, the analysis of this very important subgroup is an important and innovative addition to the existing literature.

This meta-analysis is also the first to assess immune cell biomarkers in lung cancer while stratifying studies based on their adjustment for clinically relevant covariates. Patient factors such as sex and stage may influence both the immune composition of the TME and post-surgical survival, and therefore may distort the true relationship between the TME and survival. Our study in fact showed differences in the adjusted and unadjusted estimates of CD8+ cytotoxic T cells, NK cells, CD68+ macrophages, MCs and survival. Being that different studies were used in the unadjusted and adjusted analyses it is possible that this finding could be the result of differing methodological approaches instead of confounding. However, when we assessed direct comparisons between unadjusted and adjusted findings for a single study and biomarker, adjustment for clinical covariates impacted statistical significance in $41 \%$ of instances (Supplementary Table 1). Our ability to demonstrate significantly variable findings based on the adjustment of important clinical confounders highlights the need for future research to account for several clinical factors in order to determine the independent association of immune cell biomarkers and lung cancer survival, both overall and on a per patient basis. A consensus on standard protocol for these studies is especially needed as more immune cell subtypes in relation to cancer continues to be explored.

Our study has several limitations worth discussing. As with any meta-analysis, an important limitation is the possibility of publication bias, although the funnel plots were not suggestive of publication bias, with the exception 
of CD8+ T cells (Supplementary Figures 3B-3E, 4B-4C, $5 \mathrm{~B}-5 \mathrm{E}, 6 \mathrm{~B}-6 \mathrm{C}, 7 \mathrm{~B}-7 \mathrm{D}$, and $8 \mathrm{~B}-8 \mathrm{C})$. By including only stage I-IIIA NSCLC that underwent surgical resection we minimized heterogeneity. We were also unable to directly adjust for important clinical confounders of the relationships between immune cell biomarkers and survival. While early-stage patients undergoing surgical resection are typically treatment näive, in this metaanalysis we were not able to verify this. We did stratify the results according to the presence of adjustment for important clinical confounders, but this was still a limited approach as the included studies adjusted for a variety of different clinical covariates. For instance, only $27 \%$ of eligible articles adjusted for stage, $22 \%$ for sex, $16 \%$ for histology and just 7\% for smoking. Available studies also used different cutoffs to separate high versus low biomarker infiltration, introducing additional inter-study variability. Despite these possible sources of variability, there was not statistically significant heterogeneity among studies as determined by the $\mathrm{I}^{2}$ statistic. While we attempted to investigate multiple relevant immune cell types, for some immune cell biomarkers, such as CD3+ T cells, CD20+ B cells, NK cells, TAMs and MCs, there was limited literature, thus comparisons between unadjusted and adjusted OS and DFS estimates was not possible.

Despite these limitations, by summarizing the results from several studies, we were able to overcome the limitation of small sample size observed in individual studies evaluating multiple immune cell biomarkers, and in doing so come to a more accurate estimate of their prognostic value. This meta-analysis is also the first to investigate if these immune cells are biomarkers for survival in surgically-resectable NSCLC patients, an important subgroup of patients that are likely growing as the result of screening guidelines. It is also the first to take clinical covariates into account.

Our results suggest that there are immune cells infiltrating the TME that can be considered biomarkers of survival in early-stage NSCLC. Specifically, we demonstrate the significant association of $\mathrm{CD} 8+$ cytotoxic $\mathrm{T}$ cells, CD20+B cells, NK cells and FoxP3+ T regulatory cells with survival in cases of early, resectable disease. The presence or absence of these immune cells within the TME of resected lung cancers may be used to stratify patients according to risk of recurrence and survival, with implications for who may be more likely to benefit from neo-adjuvant or adjuvant therapies [22]. Currently, there is ongoing debate about the effectiveness of immunotherapy treatment for early-stage lung cancers, with a concern that the delay in surgery to allow for immunotherapy neo-adjuvant treatment is more detrimental than beneficial to overall outcomes. However, if the immune infiltration profiles of those most likely to have disease recurrence after surgery can be identified, a patient's immune infiltration can be used to determine which patients will receive the most benefit from either adjuvant or neoadjuvant immunotherapy.
In conclusion, future randomized clinical trials should verify the prognostic value of $\mathrm{CD} 8+$ cytotoxic $\mathrm{T}$ cells, CD20+B cells, NK cells, CD68+ macrophages and FoxP3 $+\mathrm{T}$ regulatory cells and other immune components of the TME. Our meta-analysis was limited by what is published in the existing literature, but future studies should also attempt to determine the prognostic value of other immune cells that were beyond the scope of this work, including dendritic cells, Th1 cells, Th2 cells, Th17 cells and eosinophils, all of which may have an important impact on tumor immune escape and tumorigenesis, but at present are understudied [23, 24]. This will allow for clinicians to consider multi-immune cell panels when evaluating potential cancer outcomes and the need for additional treatment of patients with early-stage, surgically resected NSCLC.

\section{Author contributions}

ET, RV and RF conceptualized study design, ST and WLC performed data abstraction and statistical analysis, SG, PW and FP contributed additional expertise. All authors participated in manuscript preparation and have approved this final version.

\section{CONFLICTS OF INTEREST}

RV has received consulting honorarium from Onconova Pharmaceuticals. SG has received research support from Immune Design Corp.

\section{FUNDING}

RV was partially supported by internal grant KL02539874. FP and PW are supported by grant U24 CA210993, from the National Cancer Institute Clinical Proteomic Tumor Analysis Consortium (CPTAC).

\section{REFERENCES}

1. Bremnes RM, Busund LT, Kilvær TL, Andersen S, Richardsen E, Paulsen EE, Hald S, Khanehkenari MR, Cooper WA, Kao SC, Dønnem T. The Role of Tumor-Infiltrating Lymphocytes in Development, Progression, and Prognosis of Non-Small Cell Lung Cancer. J Thorac Oncol. 2016; 11:789-800. https:// doi.org/10.1016/i.jtho.2016.01.015. [ubMed]

2. Mittal D, Gubin MM, Schreiber RD, Smyth MJ. New insights into cancer immunoediting and its three component phases-elimination, equilibrium and escape. Curr Opin Immunol. 2014; 27:16-25. https://doi.org/10.1016/j. coi.2014.01.004. [PubMed]

3. Schreiber RD, Old LJ, Smyth MJ. Cancer Immunoediting: Integrating Immunity's Roles in Cancer Suppression and Promotion. Science. 2011; 331:1565-1570. https://doi. org/10.1126/science.1203486. [PubMed] 
4. Galon J, Angell HK, Bedognetti D, Marincola FM. The continuum of cancer immunosurveillance: prognostic, predictive, and mechanistic signatures. Immunity. 2013; 39:11-26. https://doi.org/10.1016/j.immuni.2013.07.008. [PubMed]

5. Uramoto H, Tanaka F. Recurrence after surgery in patients with NSCLC. Transl Lung Cancer Res. 2014; 3:242-249. https://doi.org/10.3978/j.issn.2218-6751.2013.12.05. [PubMed]

6. Galon J, Costes A, Sanchez-Cabo F, Kirilovsky A, Mlecnik $\mathrm{B}$, Lagorce-Pagès $\mathrm{C}$, Tosolini $\mathrm{M}$, Camus $\mathrm{M}$, Berger A, Wind P, Zinzindohoué F, Bruneval P, Cugnenc PH, et al. Type, density, and location of immune cells within human colorectal tumors predict clinical outcome. Science. 2006; 313:1960-1964. https://doi.org/10.1126/science.1129139. [PubMed]

7. Remark R, Becker C, Gomez JE, Damotte D, DieuNosjean MC, Sautès-Fridman C, Fridman WH, Powell CA, Altorki NK, Merad M, Gnjatic S. The non-small cell lung cancer immune contexture. A major determinant of tumor characteristics and patient outcome. Am J Respir Crit Care Med. 2015; 191:377-390. https://doi.org/10.1164/ rccm.201409-1671PP. [PubMed]

8. Zeng DQ, Yu YF, Ou QY, Li XY, Zhong RZ, Xie CM, Hu QG. Prognostic and predictive value of tumor-infiltrating lymphocytes for clinical therapeutic research in patients with non-small cell lung cancer. Oncotarget. 2016; 7:13765-13781. https://doi.org/10.18632/oncotarget.7282. [PubMed]

9. Soo RA, Chen Z, Yan Teng RS, Tan HL, Iacopetta B, Tai BC, Soong R. Prognostic significance of immune cells in non-small cell lung cancer: meta-analysis. Oncotarget. 2018; 9:24801-24820. https://doi.org/10.18632/oncotarget.24835. [PubMed]

10. Geng Y, Shao Y, He W, Hu W, Xu Y, Chen J, Wu C, Jiang J. Prognostic Role of Tumor-Infiltrating Lymphocytes in Lung Cancer: a Meta-Analysis. Cell Physiol Biochem. 2015; 37:1560-1571. https://doi.org/10.1159/000438523. [PubMed]

11. DerSimonian R, Laird N. Meta-analysis in clinical trials. Control Clin Trials. 1986; 7:177-188. https://doi. org/10.1016/0197-2456(86)90046-2. [PubMed]

12. Higgins JP, Thompson SG, Deeks JJ, Altman DG. Measuring inconsistency in meta-analyses. BMJ. 2003; 327:557-560. https://doi.org/10.1136/bmj.327.7414.557. [PubMed]

13. Viechtbauer W. metafor: Meta-Analysis Package for R. 2019. Available from https://CRAN.R-project.org/ package $=$ metafor.

14. Chetty R, Gatter K. CD3: Structure, function, and role of immunostaining in clinical practice. J Pathol. 1994; 173:303307. https://doi.org/10.1002/path.1711730404. [PubMed]

15. Zhu J, Paul WE. CD4 T cells: fates, functions, and faults. Blood. 2008; 112:1557-1569. https://doi.org/10.1182/ blood-2008-05-078154. [PubMed]
16. Zhang N, Bevan MJ. CD8+ T Cells: Foot Soldiers of the Immune System. Immunity. 2011; 35:161-168. https://doi. org/10.1016/j.immuni.2011.07.010. [PubMed]

17. Nelson BH. CD20+ B Cells: The Other Tumor-Infiltrating Lymphocytes. J Immunol. 2010; 185:4977-4982. https:// doi.org/10.4049/jimmunol.1001323. [PubMed]

18. Li Z, Li D, Tsun A, Li B. FOXP3+ regulatory T cells and their functional regulation. Cell Mol Immunol. 2015; 12:558-565. https://doi.org/10.1038/cmi.2015.10. [PubMed]

19. Vivier E, Tomasello E, Baratin M, Walzer T, Ugolini S. Functions of natural killer cells. Nat Immunol. 2008; 9:503510. https://doi.org/10.1038/ni1582. [PubMed]

20. Yang L, Zhang Y. Tumor-associated macrophages: from basic research to clinical application. J Hematol Oncol. 2017; 10:58. https://doi.org/10.1186/s13045-017-0430-2. [PubMed]

21. Krystel-Whittemore M, Dileepan KN, Wood JG. Mast Cell: A Multi-Functional Master Cell. Front Immunol. 2016; 6. https://doi.org/10.3389/fimmu.2015.00620. [PubMed]

22. Shahid M, Choi TG, Nguyen MN, Matondo A, Jo YH, Yoo JY, Nguyen NN, Yun HR, Kim J, Akter S, Kang I, $\mathrm{Ha}$ J, Maeng $\mathrm{CH}$, et al. An 8-gene signature for prediction of prognosis and chemoresponse in non-small cell lung cancer. Oncotarget. 2016; 7:86561-86572. https://doi. org/10.18632/oncotarget.13357. [PubMed]

23. Faruki H, Mayhew GM, Serody JS, Hayes DN, Perou CM, Lai-Goldman M. Lung Adenocarcinoma and Squamous Cell Carcinoma Gene Expression Subtypes Demonstrate Significant Differences in Tumor Immune Landscape. J Thorac Oncol. 2017; 12:943-953. https://doi.org/10.1016/j. jtho.2017.03.010. [PubMed]

24. Gnjatic S, Bronte V, Brunet LR, Butler MO, Disis ML, Galon J, Hakansson LG, Hanks BA, Karanikas V, Khleif SN, Kirkwood JM, Miller LD, Schendel DJ, et al. Identifying baseline immune-related biomarkers to predict clinical outcome of immunotherapy. J Immunother Cancer. 2017; 5:44. https://doi.org/10.1186/s40425-017-0243-4. [PubMed]

25. Takanami I, Takeuchi K, Naruke M. Mast cell density is associated with angiogenesis and poor prognosis in pulmonary adenocarcinoma. Cancer. 2000; 88:2686-2692. https:// doi.org/10.1002/1097-0142(20000615)88:12<2686::AIDCNCR6>3.0.CO;2-6. [PubMed]

26. Pelletier MP, Edwardes MD, Michel RP, Halwani F, Morin JE. Prognostic markers in resectable non-small cell lung cancer: a multivariate analysis. Can J Surg. 2001; 44:180188. [PubMed]

27. Kojima H, Shijubo N, Abe S. Thymidine phosphorylase and vascular endothelial growth factor in patients with Stage I lung adenocarcinoma. Cancer. 2002; 94:1083-1093. https:// doi.org/10.1002/cncr.10352. [PubMed]

28. Villegas FR, Coca S, Villarrubia VG, Jiménez R, Chillón MJ, Jareño J, Zuil M, Callol L. Prognostic significance of tumor 
infiltrating natural killer cells subset CD57 in patients with squamous cell lung cancer. Lung Cancer. 2002; 35:23-28. https://doi.org/10.1016/S0169-5002(01)00292-6. [ [PubMed]

29. Pelosi G, Barisella M, Pasini F, Leon ME, Veronesi G, Spaggiari L, Fraggetta F, Iannucci A, Masullo M, Sonzogni A, Maffini F, Viale G. CD117 immunoreactivity in stage I adenocarcinoma and squamous cell carcinoma of the lung: relevance to prognosis in a subset of adenocarcinoma patients. Mod Pathol. 2004; 17:711-721. https://doi. org/10.1038/modpathol.3800110. [PubMed]

30. Kojima H, Shijubo N, Yamada G, Ichimiya S, Abe S, Satoh M, Sato N. Clinical significance of vascular endothelial growth factor-C and vascular endothelial growth factor receptor 3 in patients with T1 lung adenocarcinoma. Cancer. 2005; 104:1668-1677. https://doi.org/10.1002/cncr.21366. [PubMed]

31. Petersen RP, Campa MJ, Sperlazza J, Conlon D, Joshi MB, Harpole DH, Patz EF. Tumor infiltrating Foxp3+ regulatory T-cells are associated with recurrence in pathologic stage I NSCLC patients. Cancer. 2006; 107:2866-2872. https://doi. org/10.1002/cncr.22282. [PubMed]

32. Kikuchi E, Yamazaki K, Torigoe T, Cho Y, Miyamoto M, Oizumi S, Hommura F, Dosaka-Akita H, Nishimura M. HLA class I antigen expression is associated with a favorable prognosis in early stage non-small cell lung cancer. Cancer Sci. 2007; 98:1424-1430. https://doi. org/10.1111/j.1349-7006.2007.00558.x. [PubMed]

33. Dieu-Nosjean MC, Antoine M, Danel C, Heudes D, Wislez M, Poulot V, Rabbe N, Laurans L, Tartour E, de Chaisemartin L, Lebecque S, Fridman WH, Cadranel J. Long-term survival for patients with non-small-cell lung cancer with intratumoral lymphoid structures. J Clin Oncol. 2008; 26:4410-4417. https://doi.org/10.1200/ JCO.2007.15.0284. [PubMed]

34. Shimizu K, Nakata M, Hirami Y, Yukawa T, Maeda A, Tanemoto K. Tumor-infiltrating Foxp3+ regulatory $\mathrm{T}$ cells are correlated with cyclooxygenase- 2 expression and are associated with recurrence in resected non-small cell lung cancer. J Thorac Oncol. 2010; 5:585-590. https://doi. org/10.1097/JTO.0b013e3181d60fd7. [PubMed]

35. da Costa Souza P, Parra ER, Atanazio MJ, da Silva OB, Noleto GS, Ab'Saber AM, de Morais Fernezlian S, Takagaki T, Capelozzi VL. Different morphology, stage and treatment affect immune cell infiltration and long-term outcome in patients with non-small-cell lung carcinoma. Histopathology. 2012; 61:587-596. https://doi.org/10.1111/ j.1365-2559.2012.04318.x. [PubMed]

36. Hanagiri T, Shigematsu Y, Shinohara S, Takenaka M, Oka S, Chikaishi Y, Nagata Y, Iwata T, Uramoto H, So T, Tanaka F. Clinical significance of the frequency of regulatory $\mathrm{T}$ cells in regional lymph node lymphocytes as a prognostic factor for non-small-cell lung cancer. Lung Cancer. 2013; 81:475-479. https://doi.org/10.1016/j.lungcan.2013.07.001. [PubMed]

37. Suzuki K, Kadota K, Sima CS, Nitadori J, Rusch VW, Travis WD, Sadelain M, Adusumilli PS. Clinical impact of immune microenvironment in stage I lung adenocarcinoma: tumor interleukin-12 receptor b2 (IL-12Rb2), IL-7R, and stromal FoxP3/CD3 ratio are independent predictors of recurrence. J Clin Oncol. 2013; 31:490-498. https://doi. org/10.1200/JCO.2012.45.2052. [PubMed]

38. Feng PH, Yu CT, Wu CY, Lee MJ, Lee WH, Wang LS, Lin SM, Fu JF, Lee KY, Yen TH. Tumor-associated macrophages in stage IIIA pN2 non-small cell lung cancer after neoadjuvant chemotherapy and surgery. Am J Transl Res. 2014; 6:593-603. [PubMed]

39. Germain C, Gnjatic S, Tamzalit F, Knockaert S, Remark R, Goc J, Lepelley A, Becht E, Katsahian S, Bizouard G, Validire P, Damotte D, Alifano M, et al. Presence of $\mathrm{B}$ cells in tertiary lymphoid structures is associated with a protective immunity in patients with lung cancer. Am J Respir Crit Care Med. 2014; 189:832-844. https://doi. org/10.1164/rccm.201309-16110C. [PubMed]

40. Hanagiri T, Fukumoto M, Koyanagi Y, Furutani Y, Tanaka F. Regulatory T-cells and micrometastasis in lymph nodes of stage I NSCLC. Anticancer Res. 2014; 34:7185-7190. [PubMed]

41. Lee MC, Buitrago DH, Kadota K, Ujiie H, Woo K, Sima CS, Travis WD, Jones DR, Adusumilli PS. The tumor immune microenvironment in octogenarians with stage I non-small cell lung cancer. Oncoimmunology. 2014; 3:e967142. https://doi.org/10.4161/21624011.2014.96714 2. [PubMed]

42. Djenidi F, Adam J, Goubar A, Durgeau A, Meurice G, de Montpréville V, Validire P, Besse B, Mami-Chouaib F. CD8+CD103+ tumor-infiltrating lymphocytes are tumorspecific tissue-resident memory $\mathrm{T}$ cells and a prognostic factor for survival in lung cancer patients. J Immunol. 2015; 194:3475-3486. https://doi.org/10.4049/jimmunol.1402711. [PubMed]

43. Hernández-Prieto $\mathrm{S}$, Romera $\mathrm{A}$, Ferrer $\mathrm{M}$, Subiza JL, López-Asenjo JA, Jarabo JR, Gómez AM, Molina EM, Puente J, González-Larriba JL, Hernando F, Pérez-Villamil B, Díaz-Rubio E, et al. A 50-gene signature is a novel scoring system for tumor-infiltrating immune cells with strong correlation with clinical outcome of stage I/II nonsmall cell lung cancer. Clin Transl Oncol. 2015; 17:330338. https://doi.org/10.1007/s12094-014-1235-1. [PubMed]

44. Kadota K, Nitadori JI, Ujiie H, Buitrago DH, Woo KM, Sima CS, Travis WD, Jones DR, Adusumilli PS. Prognostic Impact of Immune Microenvironment in Lung Squamous Cell Carcinoma: Tumor-Infiltrating CD10+ Neutrophil/ CD20+ Lymphocyte Ratio as an Independent Prognostic Factor. J Thorac Oncol. 2015; 10:1301-1310. https://doi. org/10.1097/JTO.0000000000000617. [PubMed]

45. Kim MY, Koh J, Kim S, Go H, Jeon YK, Chung DH. Clinicopathological analysis of PD-L1 and PD-L2 expression in pulmonary squamous cell carcinoma: Comparison with tumor-infiltrating T cells and the status of oncogenic drivers. Lung Cancer. 2015; 88:24-33. https:// doi.org/10.1016/j.lungcan.2015.01.016. [ [ PubMed] 
46. Donnem T, Hald SM, Paulsen EE, Richardsen E, Al-Saad S, Kilvaer TK, Brustugun OT, Helland A, Lund-Iversen M, Poehl M, Olsen KE, Ditzel HJ, Hansen O, et al. Stromal CD8+ T-cell Density-A Promising Supplement to TNM Staging in NonSmall Cell Lung Cancer. Clin Cancer Res. 2015; 21:26352643. https://doi.org/10.1158/1078-0432.CCR-14-1905. [PubMed]

47. Li Y, Sun BS, Pei B, Li CG, Zhang ZF, Yin YS, Wang CL. Osteopontin-expressing macrophages in non-small cell lung cancer predict survival. Ann Thorac Surg. 2015; 99:1140 1148. https://doi.org/10.1016/j.athoracsur.2014.11.054. [PubMed]

48. O'Callaghan DS, Rexhepaj E, Gately K, Coate L, Delaney D, O'Donnell DM, Kay E, O'Connell F, Gallagher WM, O’Byrne KJ. Tumour islet Foxp3+ T-cell infiltration predicts poor outcome in nonsmall cell lung cancer. Eur Respir J. 2015; 46:1762-1772. https://doi. org/10.1183/13993003.00176-2014. [PubMed]

49. Paulsen EE, Kilvaer T, Khanehkenari MR, Maurseth RJ, AlSaad S, Hald SM, Al-Shibli K, Andersen S, Richardsen E, Busund LT, Bremnes R, Donnem T. CD45RO(+) Memory T Lymphocytes-a Candidate Marker for TNM-Immunoscore in Squamous Non-Small Cell Lung Cancer. Neoplasia. 2015; 17:839-848. $\quad$ https://doi.org/10.1016/j.neo.2015.11.004. [PubMed]

50. Tian C, Lu S, Fan Q, Zhang W, Jiao S, Zhao X, Wu Z, Sun L, Wang L. Prognostic significance of tumor-infiltrating CD8+ or CD3 + T lymphocytes and interleukin-2 expression in radically resected non-small cell lung cancer. Chin Med J (Engl). 2015; 128:105-110. $\quad$ https://doi.org/10.4103/0366-6999.147828. [PubMed]

51. Ameratunga M, Asadi K, Lin X, Walkiewicz M, Murone C, Knight S, Mitchell P, Boutros P, John T. PD-L1 and Tumor Infiltrating Lymphocytes as Prognostic Markers in Resected NSCLC. PLoS One. 2016; 11. https://doi.org/10.1371/ journal.pone.0153954. [PubMed]

52. Kinoshita T, Muramatsu R, Fujita T, Nagumo H, Sakurai T, Noji S, Takahata E, Yaguchi T, Tsukamoto N, Kudo-Saito C, Hayashi Y, Kamiyama I, Ohtsuka T, et al. Prognostic value of tumor-infiltrating lymphocytes differs depending on histological type and smoking habit in completely resected non-small-cell lung cancer. Ann Oncol. 2016; 27:21172123. https://doi.org/10.1093/annonc/mdw319. [PubMed]

53. Parra ER, Behrens C, Rodriguez-Canales J, Lin H, Mino B, Blando J, Zhang J, Gibbons DL, Heymach JV, Sepesi B, Swisher SG, Weissferdt A, Kalhor N, et al. Image Analysisbased Assessment of PD-L1 and Tumor-Associated Immune Cells Density Supports Distinct Intratumoral Microenvironment Groups in Non-small Cell Lung Carcinoma Patients. Clin Cancer Res. 2016; 22:62786289. https://doi.org/10.1158/1078-0432.CCR-15-2443. [PubMed]

54. Teng F, Meng X, Wang X, Yuan J, Liu S, Mu D, Zhu H, Kong L, Yu J. Expressions of CD8+TILs, PD-L1 and Foxp3+TILs in stage I NSCLC guiding adjuvant chemotherapy decisions. Oncotarget. 2016; 7:64318-64329. https://doi.org/10.18632/oncotarget.11793. [PubMed]

55. Usó M, Jantus-Lewintre E, Bremnes RM, Calabuig S, Blasco A, Pastor E, Borreda I, Molina-Pinelo S, Paz-Ares L, Guijarro R, Martorell M, Forteza J, Camps C, et al. Analysis of the immune microenvironment in resected non-small cell lung cancer: the prognostic value of different $\mathrm{T}$ lymphocyte markers. Oncotarget. 2016; 7:52849-52861. https://doi. org/10.18632/oncotarget.10811. [PubMed]

56. Yang $\mathrm{CY}$, Lin MW, Chang YL, Wu CT, Yang PC. Programmed cell death-ligand 1 expression is associated with a favourable immune microenvironment and better overall survival in stage I pulmonary squamous cell carcinoma. Eur J Cancer. 2016; 57:91-103. https://doi. org/10.1016/j.ejca.2015.12.033. [PubMed]

57. Talebian Yazdi M, van Riet S, van Schadewijk A, Fiocco M, van Hall T, Taube C, Hiemstra PS, van der Burg SH. The positive prognostic effect of stromal CD8+ tumorinfiltrating T cells is restrained by the expression of HLA-E in non-small cell lung carcinoma. Oncotarget. 2016; 7:3477-3488. https://doi.org/10.18632/oncotarget.6506. [PubMed]

58. Huang Z, Yu H, Zhang J, Jing H, Zhu W, Li X, Kong L, Xing L, Yu J, Meng X. Correlation of cancer stem cell markers and immune cell markers in resected non-small cell lung cancer. J Cancer. 2017; 8:3190-3197. https://doi. org/10.7150/jca.20172. [PubMed]

59. Kinoshita T, Kudo-Saito C, Muramatsu R, Fujita T, Saito M, Nagumo H, Sakurai T, Noji S, Takahata E, Yaguchi T, Tsukamoto N, Hayashi Y, Kaseda K, et al. Determination of poor prognostic immune features of tumour microenvironment in non-smoking patients with lung adenocarcinoma. Eur J Cancer. 2017; 86:15-27. https://doi. org/10.1016/j.ejca.2017.08.026. [PubMed]

60. Koh J, Kim S, Kim MY, Go H, Jeon YK, Chung DH. Prognostic implications of intratumoral CD103+ tumorinfiltrating lymphocytes in pulmonary squamous cell carcinoma. Oncotarget. 2017; 8:13762-13769. https://doi. org/10.18632/oncotarget.14632. [PubMed]

61. Sepesi B, Cuentas EP, Canales JR, Behrens C, Correa AM, Vaporciyan A, Weissferdt A, Kalhor N, Moran C, Swisher S, Wistuba I. Programmed Death Cell Ligand 1 (PD-L1) Is Associated With Survival in Stage I Non-Small Cell Lung Cancer. Semin Thorac Cardiovasc Surg. 2017; 29:408-415. https://doi.org/10.1053/j.semtcvs.2017.05.008. [PubMed]

62. Ye SL, Li XY, Zhao K, Feng T. High expression of CD8 predicts favorable prognosis in patients with lung adenocarcinoma: A cohort study. Medicine (Baltimore). 2017; 96:e6472. https://doi.org/10.1097/ MD.0000000000006472. [PubMed]

63. Barua S, Fang P, Sharma A, Fujimoto J, Wistuba I, Rao AUK, Lin SH. Spatial interaction of tumor cells and regulatory $\mathrm{T}$ cells correlates with survival in non-small cell lung cancer. Lung Cancer. 2018; 117:73-79. https://doi. org/10.1016/j.lungcan.2018.01.022. [ [PubMed] 
64. Jackute J, Zemaitis M, Pranys D, Sitkauskiene B, Miliauskas S, Vaitkiene S, Sakalauskas R. Distribution of M1 and M2 macrophages in tumor islets and stroma in relation to prognosis of non-small cell lung cancer. BMC Immunol. 2018; 19:3. https://doi.org/10.1186/s12865-018-0241-4. [PubMed]

65. Mazzaschi G, Madeddu D, Falco A, Bocchialini G, Goldoni M, Sogni F, Armani G, Lagrasta CA, Lorusso B, Mangiaracina C, Vilella R, Frati C, Alfieri R, et al. Low PD-1 Expression in Cytotoxic CD8+ TumorInfiltrating Lymphocytes Confers an Immune-Privileged Tissue Microenvironment in NSCLC with a Prognostic and Predictive Value. Clin Cancer Res. 2018; 24:407419. https://doi.org/10.1158/1078-0432.CCR-17-2156. [PubMed]

66. Su H, Xie H, Dai C, Ren Y, She Y, Xu L, Chen D, Xie D, Zhang L, Jiang G, Chen C. Characterization of TIM-3 expression and its prognostic value in patients with surgically resected lung adenocarcinoma. Lung Cancer. 2018; 121:18-24. https://doi.org/10.1016/j. lungcan.2018.04.009. [PubMed]
67. Matsubara T, Takada K, Azuma K, Takamori S, Toyokawa G, Haro A, Osoegawa A, Tagawa T, Kawahara A, Akiba J, Okamoto I, Nakanishi Y, Oda Y, et al. A Clinicopathological and Prognostic Analysis of PD-L2 Expression in Surgically Resected Primary Lung Squamous Cell Carcinoma. Ann Surg Oncol. 2019; 26:1925-1933. https://doi.org/10.1245/ s10434-019-07257-3. [PubMed]

68. Meng X, Gao Y, Yang L, Jing H, Teng F, Huang Z, Xing L. Immune Microenvironment Differences Between Squamous and Non-squamous Non-small-cell Lung Cancer and Their Influence on the Prognosis. Clin Lung Cancer. 2019; 20:4858. https://doi.org/10.1016/j.cllc.2018.09.012. [PubMed]

69. Cao L, Che X, Qiu X, Li Z, Yang B, Wang S, Hou K, Fan Y, Qu X, Liu Y. M2 macrophage infiltration into tumor islets leads to poor prognosis in non-small-cell lung cancer. Cancer Manag Res. 2019; 11:6125-6138. https://doi. org/10.2147/CMAR.S199832. [PubMed] 